\title{
Masseter muscle surface electromyography in college students with a high degree of anxiety and temporomandibular disorder
}

\author{
Eduarda de Lima Amarante(1) \\ Jully Anne Soares de Lima ${ }^{(1)}$ \\ Rafael Nóbrega Bandeira(1) \\ Ana Paula Arruda de Moura(1) \\ Luciane Spinelli de Figueiredo Pessoa ${ }^{(1)}$ \\ Leandro de Araújo Pernambuco(1) \\ Giorvan Ânderson dos Santos Alves ${ }^{(1)}$
}

(1) Universidade Federal da Paraíba, João Pessoa, Paraíba, Brasil.

Conflict of interest: Nonexistent

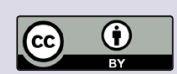

Received on: May 16, 2017

Accepted on: November 3, 2017

Mailing address:

Giorvan Ânderson dos Santos Alves

Rua Josemar Rodrigues de Carvalho, 245Bairro Jardim Oceania

CEP: 58037-415 - João Pessoa, Paraíba, Brasil

E-mail: anderson_ufpb@yahoo.com.br

\section{ABSTRACT}

Objective: to compare the electrical activity of masseter muscles, bilaterally, according to the presence or absence of Temporomandibular Disorder (TMD) in college students with a high degree of anxiety.

Methods: the study was conducted with a randomized sample of 31 Speech Therapy students aged between 17 and 32 years; $61.3 \%(n=19)$ were females and $38.7 \%$ $(n=12)$ were males. They were divided into two groups, Group 1 (G1), comprising 11 students with TMD, and Group 2 (G2), composed of 20 students without TMD. The college students answered the State-Trait Anxiety Inventory (STAl) for anxiety investigation, and were evaluated by the protocol Research Diagnostic Criteria for Temporomandibular Disorders (RDC/TMD) for TMD diagnosis. The evaluation of muscular electrical activity took into account the records in the conditions of rest, Sustained Maximum Voluntary Activity (SMVA) and habitual chewing (HC). The data were analyzed using the version 22 IBM Statistical Package for Social Sciences (SPSS) software. The statistical analysis was performed using Student $t$ test to compare means between groups, considering $<0,05$ as the significant $p$-value.

Results: college students, of both groups, presented high levels of anxiety traits. Significant statistical differences were observed on the percentage of electrical activity of right masseter muscle in chewing function, as well as muscle fibers recruitment during chewing, which were higher on the group without TMD.

Conclusion: college students with TMD and a high degree of anxiety presented lower means of masseter muscle electromyografic activity during chewing, in most conditions assessed, as compared to volunteers without TMD, except for the left masseter muscle in rest and chewing.

Keywords: Temporomandibular Joint Dysfunction Syndrome; Anxiety; Students; Electromyography 


\section{INTRODUCTION}

Temporomandibular disorder (TMD) is a term referring to a series of functional changes related to the Temporomandibular Joint (TMJ), chewing muscles and associated structures. It is characterized by a set of signs and symptoms with great variation between subjects, and by negative repercussions on quality of life. In general, the clinical condition consists of pain or discomfort in the masticatory muscle or TMJ, muscle spasm, inadequate occlusion, headache, deviations and joint noises (such as cracking and crackling) during mastication and opening of the oral cavity, restrictions on the performance of mandibular movements and masticatory, vocal and auditory difficulties ${ }^{1-5}$.

This dysfunction is more common in individuals aged 20-45 years, with a higher prevalence in females ${ }^{3}$. The American Academy of Orofacial Pain estimates that $40-75 \%$ of the US population has some type of TMD signs and that $33 \%$ have some symptoms ${ }^{1}$. However, it is estimated that only $3.6 \%$ to $7 \%$ require or seek some type of intervention ${ }^{2}$.

The etiology of TMD is multifactorial, and is associated with anatomical and neuromuscular aspects, deleterious habits, postural deviations, trauma and psychosocial changes ${ }^{6,7}$. The physiological and structural tolerance of the individual is the aspect that will determine whether or not the patient will develop the disorder. Due to a combination of factors, intervention should be performed from a biopsychosocial perspective, which takes into account pathological, physiological, social, cultural and psychological components.

Literature data show evidences of a relationship between TMD and emotional factors such as anxiety6,8-10. It can be defined as a condition of alertness determined by the presence of an internal conflict in face of a stimulus which may be interpreted as an eminent or threatening danger ${ }^{11}$. It becomes pathological when present at high levels, disproportionate to the circumstance that originated it, remaining persistent even when there is no specific situation to which it is directed $^{12}$. This scenario may be especially worrisome in college students, because it is a population subjected to situations that generate high levels of anxiety, such as intense academic demands, good performance requirements, increased responsibilities and personal, familiar and social pressures ${ }^{4-8}$.

It is known that anxiety may be a triggering, precipitating or perpetuating factor of $\mathrm{TMD}^{6,9}$, and may change the level of tolerance to pain ${ }^{3}$, and thus modulate the activity of muscles acting on the TMJ, such as the masseter. Therefore, it can be assumed that in college students exposed to a high degree of anxiety, the electromyographic activity of the masseter is different according to the presence or absence of TMD.

In a study that sought to analyze the electromyographic activity of masseter muscles and the anterior part of the temporal in an anxiety state, The StateTrait Anxiety Inventory was used with 16 volunteers free of signs and symptoms of temporomandibular dysfunction. The activities of simultaneous bilateral mastication, habitual chewing and voluntary contraction were performed in maximum intercuspation at different periods. The authors concluded that trait and state anxiety may influence electromyographic records even in non-experimental situations ${ }^{13}$.

Another study, also analyzing the aspects of anxiety (STAI) and temporomandibular dysfunction (RDC/ TMD) using electromyographic recordings, found as a result from the evaluation of physical aspects lower mean values for Pressure Pain Threshold and higher means for Pain to Palpation in volunteers with TMD, both indicators of higher levels of pain, and lower mean frenulum values of the left masseter muscle in the group with temporomandibular dysfunction. Regarding psychological aspects, both State-Anxiety and TraitAnxiety were statistically higher in the Group with $\mathrm{TMD}^{14}$.

When analyzing 16 volunteers free from signs and symptoms of temporomandibular dysfunction, they were diagnosed according to the Diagnostic Criteria for Research on Temporomandibular Dysfunction (RDC/ TMD), but also with anxiety, by the State-Trait Anxiety Inventory (STAI). Regarding anxiety, the results showed an inverse association between the variable activation time and trait-anxiety levels during both activities and a direct association between the variable maximum instant and trait-anxiety levels during simultaneous bilateral chewing activities, habitual chewing and voluntary contraction in maximum intercuspation. Only the anterior part of the temporalis muscle presented a direct relation between the variable maximum instantaneous and state-anxiety during habitual chewing; during simultaneous bilateral chewing, the variable activation time showed an inverse relation for the same muscle. The authors concluded that trait and state anxiety may influence electromyographic records even in non-experimental situations ${ }^{15}$.

In light of the above, the evaluation of electromyographic activity may contribute to the diagnosis 
and to a more precise, early and effective monitoring of muscular, biomechanical and sensorial changes associated with $\mathrm{TMD}^{16-18}$. In addition, research addressing the analysis of temporomandibular anxiety and temporomandibular dysfunction using electromyographic recording, also in men, becomes necessary, since the literature contemplates satisfactory investigations on women. Therefore, the objective of this study is to compare the electrical activity of masseter muscles bilaterally according to the presence or absence of TDM in college students with high degree of anxiety.

\section{METHODS}

The research follows the recommendations of the criteria and requirements established by the Resolution no. 466/12 of the National Health Council (CNS). It was previously submitted to the Ethics Committee of Research with Human Beings of the Health Sciences Center of the Federal University of Paraíba for assessment, and approved under protocol no. 0144/12, CAAE no. 03117312.1.0000.5188.

The study was conducted with college students of Speech Therapy of a Public University in the Brazilian Northeast region. The sample was composed of 31 random volunteers aged between 17 and 32 years (mean of $22.1 \pm 3.62$ years); $61.3 \%(n=19)$ were female and $38.7 \%(n=12)$ were male. They were divided into two Group 1 (G1), composed of students with TMD, and Group 2 (G2), composed of students without TMD.

As eligibility criteria for both groups, we considered no diagnosis of neuromuscular and/or degenerative diseases, not having suffered trauma in the temporomandibular region, not having autoimmune disease that could compromise joints, not having received treatment for TMD, and being a student duly enrolled in the Speech-Language Pathology course.

To investigate the presence/absence of anxiety, college students answered the State-Trait Anxiety Inventory $(\mathrm{STAl})^{19}$ using a validated version for Brazilian Portuguese ${ }^{20,21}$. The instrument comprises 40 statements about the subject's feelings, divided into two parts. Each part consists of 20 descriptive statements regarding personal feelings, which the subjects rank in relation to the intensity with which they are occurring at that moment (part I - state-anxiety) or in relation to the frequency with which they occur generally (part II - trace-anxiety) using a Likert scale ranging from 1 to 4 points ${ }^{22}$. The cutoff points for the classification of the degree of anxiety are $\leq 40$ for low anxiety and $\geq 41$ for high anxiety ${ }^{23}$. In this study, only volunteers with high anxiety were included.

For the diagnosis of TMD, all subjects were evaluated using the protocol Research Diagnostic Criteria for Temporomandibular Disorders (RDC/TMD), translated and validated for Brazilian Portuguese ${ }^{24}$. The RDC/TMD contains two axes: Axis I consists of physical diagnosis through standardized clinical examination applied by a trained researcher, and may be used to classify the individual according to the clinical conditions of TMD into three groups: Group I - Muscle dysfunctions (a. Myofascial pain, b. Myofascial pain with opening limitation), Group II - Displacement of the articular disc (a. Disc displacement with reduction, b. Disc displacement without reduction, with limited opening; c. Disc displacement without reduction, without limited opening), and Group III - Arthralgia, arthritis and arthrosis (a. Arthralgia, b. Osteoarthritis of TMD, c. Osteoarthrosis of TMD). To be allocated in Group 1 (with TMD), individuals should belong to at least one of the RDC/TMD axis 1 groups, otherwise they were allocated to Group 2 (Without TMD). Axis II data, which assess the psychosocial profile of the volunteers, were not used for this study.

After completing the questionnaires, the volunteers were submitted to electromyographic evaluation of the surface of the right and left masseter muscles. We used the Miotool 200/400 electromyograph, MIOTEC ${ }^{\circledR}$ (Rio Grande do Sul, Brazil), composed of four channels connected via USB communication cable to a HP Pavilion notebook, 14-V066BR, 8 GB RAM, 1 TB HD, Processor Intel Core i7-4510U and Microsoft Windows operating system, version 7 . The electromyographic signals were collected by the data acquisition system of the equipment using a windowing of 32 and a gain of 1,000 for each channel. A ground cable (reference) was used to avoid electromagnetic interference during the examination, and two equipment channels were connected to two claw-connected SDS500 sensors. The surface electrodes were MEDITRACE ${ }^{\circledR}$ (Kendall, Canada), disposable, children's standard, made of silver-silver chloride (Ag-AgCl), immersed in a conductive gel, responsible for capturing and conducting the electromyographic surface signal. The signal analysis was performed using the software Miograph, MIOTEC ${ }^{\circledR}$ (Rio Grande do Sul, Brazil).

For the collection of electromyographic surface signs, the volunteer was accommodated comfortably in a chair, with the torso erect, feet resting on the floor, and the head oriented along the horizontal plane of 
Frankfurt, parallel to the ground, not being able to see the screen of the notebook. Then, the skin was cleaned with cotton soaked in $70^{\circ}$ alcohol to remove any material that could promote impedance to signal capturing. The placement of electrodes began by the ground electrode, positioned in the olecranon of the ulna of the right arm of the volunteer. Subsequently, the electrodes were fixed in the right and left masseters. The fixation of electrodes obeyed the bipolar configuration (with a 1.5-centimeter distance) in the region of the muscular belly of the masseters, longitudinally to the muscular fibers. To locate the region in which the electrode would be fixed, a trained investigator instructed the volunteer to keep the teeth in occlusal contact, thus enabling palpating the more robust region of the masseter, corresponding to the neuromuscular junction ${ }^{25}$. The sensors with claws were then fixed, obeying the same order of placement as the electrodes.

The evaluation of muscular electric activity considered records in conditions of rest, Sustained
Maximum Voluntary Activity (SMVA) and habitual chewing $(\mathrm{HC})$, according to the protocol used ${ }^{26}$, as shown in Figure 1.

\section{FIGURE 1.}

For rest analysis and SMVA, three seconds of the electromyographic signal were selected, excluding the first and last seconds of the recording. A time of 5 seconds for the collection of the signal is important to avoid muscular fatigue, since it is a relatively short time of contraction. In addition, it is sufficient to achieve the required maximum electromyographic amplitude ${ }^{27}$. For the analysis of the mastication record, the selection of five masticatory cycles was performed. The signals were initially calculated from the raw signal (Raw) of the mean amplitude value, measured in microvolts $(\mu \mathrm{V})$, later transformed into Root Mean Square (RMS), representing the calculation of root mean square.

\section{Test 01 - Rest}

The participant was instructed to stay in the usual position, without speaking, chewing or swallowing for 5 seconds, while the electromyographic examination was performed.

\section{Test 02 - Sustained Maximum Voluntary Activity (SMVA) (100\%)}

The participant was instructed to keep occlusal contact (biting forcefully), contracting the masticatory muscles bilaterally and simultaneously, with a maximum habitual intercuspation, maintaining the contraction for 5 seconds ${ }^{26}$.

\section{Test 03 - Habitual Chewing (HC)}

The patient was instructed to make the usual incision and keep the usual chewing for 10 seconds. The food used was loaves of French bread.

Figure 1. Stages of the electromyographic evaluation protocol of masseter muscles

The task of maximal voluntary isometric contraction applied to the head and neck musculature is now called SMVA ${ }^{28}$, and was used for the normalization of electromyographic signals. The normalization of data allows a comparison with some standard value ${ }^{27}$. The choice for this technique is based on the comparisons to be made in the study. In addition, it is possible to convert absolute values into percentages of a reference value $^{26,28}$. In this study, the SMVA represented $100 \%$ of the electrical activity of the masseter muscle on each side. For normalization, the proportion of muscular electrical activity of the chewing procedure was calculated bilaterally in relation to the SMVA. At this proportion, it is considered as $100 \%$, and a simple rule of three is performed to obtain the percentage of habitual resting and chewing activities ${ }^{27}$.

Data were organized in spreadsheets using the software IBM Statistical Package for Social Sciences (SPSS), version 22, trial, in which a descriptive statistical analysis was performed to obtain mean and standard deviation data. In addition, the Student t test was used to compare the means between Groups 1 (with TMD) and 2 (without TMD). The choice for this test followed the statistical principle of normality, verified as positive by the Shapiro-Wilk test. For all statistical tests, the data were considered significant when the $p$-value was lower than $5 \%$. 


\section{RESULTS}

From the assessment of TMD by RDC/TMD, Group I was composed of 11 individuals with TMD and Group II was composed of 20 individuals without TMD. The clinical conditions of patients with TMD were myofascial pain, disc displacement with right or left reduction, myofascial pain, displacement of the left disc with reduction, and myofascial pain and arthralgia.

Table 1 shows the values of the State-Trait Anxiety Inventory of voluntary students for the groups with and without TMD.

Table 1. Distribution of State-Trait Anxiety Inventory means for college students with and without Temporomandibular Disorder

\begin{tabular}{ccccc}
\hline Variables & Group & Mean & SD & P value* \\
\hline \multirow{2}{*}{ STAl I } & with TMD & 43.73 & 4.36 & 0.42 \\
& without TMD & 42.20 & 5.26 & \multirow{2}{*}{0.94} \\
\hline
\end{tabular}

Caption: SD - Standard deviation; TMD - temporomandibular disorder

* Student $t$ test, $p<0.05$

In the results of differences in electromyographic activity between Group I and II of masseter muscles under resting conditions, SMVA, chewing and percentage of maximum electrical activity, it can be observed that the mean values were higher in the Group II for all variables studied on the right side. Regarding the left masseter, electromyographic means were higher among the students of the Group II in the
SMVA and percentage of recruitment in mastication. In Group I, the greatest means occurred for the remaining and the chewing variables.

However, statistically significant differences were observed for the percentage of maximal electrical activity of the right masseter in mastication and percentage of masticatory muscle recruitment, with higher means in the Group without TMD (Table 2). 
Table 2. Descriptive data and comparison of means of the muscular activity of the masseter in the accomplishment of different tasks in college students with and without temporomandibular disorder

\begin{tabular}{|c|c|c|c|c|c|}
\hline & iables & Group & Mean & $S^{2}$ & P value $^{4}$ \\
\hline \multirow{12}{*}{ Right Masseter } & \multirow{3}{*}{$\mathrm{S}_{\mathrm{MVA}}{ }^{1}$} & With TMD ${ }^{3}$ & 58.99 & 48.25 & \multirow{3}{*}{0.45} \\
\hline & & Without TMD & 81.01 & 89.28 & \\
\hline & & Sample & 73.19 & 77.06 & \\
\hline & \multirow{3}{*}{ Rest } & With TMD & 3.64 & 1.17 & \multirow{4}{*}{0.28} \\
\hline & & Without TMD & 5.80 & 6.02 & \\
\hline & & Sample & 5.04 & 5.24 & \\
\hline & \multirow{4}{*}{ Chewing (in microvolts) } & With TMD & 36.57 & 30.59 & \\
\hline & & Without TMD & 65.46 & 39.36 & \multirow[t]{2}{*}{$0.04^{*}$} \\
\hline & & Sample & 55.21 & 38.61 & \\
\hline & & With TMD & 65.97 & 24.13 & \multirow{3}{*}{$0.04^{\star}$} \\
\hline & \multirow[t]{2}{*}{$\%{ }^{5}$ chewing } & Without TMD & 195.91 & 270.63 & \\
\hline & & Sample & 149.80 & 224.89 & \\
\hline \multirow{12}{*}{ Left Masseter } & \multirow{3}{*}{$\mathrm{S}_{\mathrm{MVA}}$} & With TMD & 92.42 & 44.44 & \multirow{3}{*}{0.57} \\
\hline & & Without TMD & 114.60 & 124.93 & \\
\hline & & Sample & 106.73 & 103.25 & \\
\hline & \multirow{3}{*}{ Rest } & With TMD & 7.77 & 11.27 & \multirow{3}{*}{0.44} \\
\hline & & Without TMD & 5.55 & 4.56 & \\
\hline & & Sample & 6.34 & 7.53 & \\
\hline & \multirow{4}{*}{ Chewing (in microvolts) } & With TMD & 88.31 & 42.22 & \multirow{4}{*}{0.72} \\
\hline & & Without TMD & 82.59 & 42.53 & \\
\hline & & Sample & 84.62 & 41.80 & \\
\hline & & With TMD & 135.91 & 121.07 & \\
\hline & \multirow[t]{2}{*}{$\%^{5}$ chewing } & Without TMD & 138.91 & 117.63 & \multirow[t]{2}{*}{0.94} \\
\hline & & & 137.85 & 116.84 & \\
\hline
\end{tabular}

Caption: ${ }^{1}$ Sustained Maximum Voluntary Activity; ${ }^{2}$ standard deviation; ${ }^{3}$ Tempomandibular disorder, ${ }^{4}$ Student $\mathrm{t}$ test, $\mathrm{p}<0.05$;

* Significant data; ${ }^{5}$ Percentage of electrical activity

\section{DISCUSSION}

Given the results, the data showed that college students have high levels of anxiety. Several studies $^{8,22,28-33}$ have been conducted with these individuals due to a great repercussion of emotional factors on academic performance. Also noteworthy are the maturational transformations experienced by students ${ }^{19}$ arising from the transition between adolescence and adulthood. In the data of this research, both Group I and II presented a high level of state and trait anxiety. Several studies report anxiety as a possible etiology for the development of TMD, acting as an important collaborator for the installation and maintenance of this dysfunction $4-6,8,9,13-15$. The prevalence of individuals with TMD and anxiety is significantly higher in individuals with TMD without anxiety' ${ }^{9}$. On the other hand, there are studies ${ }^{34,35}$ that did not report differences between the anxiety levels of TMD symptomatic subjects and asymptomatic subjects.
Participants with TMD had a lower electrical activity in the right masseter muscle than asymptomatic subjects in all the conditions studied. The maximum electrical activity that the masseter requests in chewing, in relation to the normalization value, shows that individuals with TMD present a potential lag when compared to the control group. These data are close to those reported by other studies, which show a low functional efficiency of the muscles in TMD patients ${ }^{36}$, and statistically significant differences among healthy individuals who have a higher mean bite force value in relation to TMD patients ${ }^{37}$. In many individuals, the reduction in strength occurs due to the pain, a limiting factor in the performance of bite force ${ }^{38}$

The electromyographic activity of the left masseter muscle at a resting state presents a pattern of greater muscular electrical activity in relation to the right side, a result of joint disharmony, when compared with healthy individuals, which indicates an increase in the basal musculature tone. This finding is compatible with 
others found in the literature comparing the electromyographic activity of masticatory muscles of subjects with and without TMD ${ }^{37}$. The mean of SMVA was higher in the control group; therefore, individuals with TMD have a significantly reduced ability to tighten the jaw ${ }^{37}$, which could be interpreted as a defense mechanism of the injured system ${ }^{39}$. Subjects with pain in masticatory muscles change their muscle recruitment, corroborating with the concept that the neuromuscular system changes in patients with craniomandibular disorders ${ }^{40}$.

However, even when amplitude averages were higher in Group I, in the left masseter at rest and in mastication, the subjects in Group II achieved a greater efficacy regarding the percentage of their maximum electrical activity in relation to the value of normalization.

\section{CONCLUSION}

In this study, we observed that there were differences in the electromyographic means of the masseter muscle between subjects with and without TMD, all of which were lower in individuals with TMD, except for the left masseter at rest and chewing. Such data may indicate that subjects with temporomandibular disorders present a changed neuromuscular system when evaluated by surface electromyography.

The high index of trait and state anxiety, as well as temporomandibular dysfunctions, in college students calls attention to the need for interdisciplinary interventions in this population, in order to prevent this change and promote physical and psychic quality of life.

\section{REFERENCES}

1. Ferreira FB, Cruz LMP, Urban VM, Fernandes $\mathrm{F}$, Campanha $\mathrm{NH}$, Jorge JH. Prevalência das desordens temporomandibulares em graduandos da Universidade Estadual de Ponta Grossa. Arq Odontol. 2012;48(1):13-8.

2. Webster G. Avaliação do efeito do tratamento de distúrbios temporomandibulares sobre o zumbido. Arq. Int. Otorrinolaringol. 2011;15(3):327-32.

3. Coronatto EAS, Zuccolotto MCC, Bataglión C, Bitondi MBM. Associação entre disfunção temporomandibular e ansiedade: estudo epidemiológico em pacientes edêntulos. Int J Dent. 2009;8(1):610.

4. Goyatá FR, Taira NV, Almeida S, Silva DM, Taira CV. Avaliação de sinais e sintomas de disfunção temporomandibular entre os acadêmicos do curso de odontologia da universidade Severino Sombra, Vassouras-RJ. Int J Dent. 2010;9(4):181-6.

5. Bezerra BPN, Ribeiro AIAM, Farias ABL, Fontes LBC, Nascimento SR, Nascimento AS et al. Prevalência da disfunção temporomandibular e de diferentes níveis de ansiedade em estudantes universitários. Rev Dor. 2012;13(3):235-42.

6. Pasinato F, Corrêa ECR, Souza JA. Avaliação do estado e traço de ansiedade em indvíduos com disfunção temporomandibular e assintomáticos. Saúde. 2009;35(1):10-5.

7. Medeiros SP, Batista AUD, Forte FDS. Prevalência de sintomas de disfunção temporomandibular e hábitos parafuncionais em estudantes universitários. RGO - Rev Gaúcha Odontol. 2011;59(2):201-8.

8. Fernandes AUR, Garcia AR, Zuim PRJ, Cunha LDP, Marchiori AV. Desordem temporomandibular e ansiedade em graduandos de odontologia. Cienc Odontol Bras. 2007;10(1):70-7.

9. Simm W, Lopes LKC. Avaliação e correlação entre sintomas de disfunção temporomandibular e o índice de ansiedade e depressão em alunos do curso de odontologia do Centro Universitário de Maringá. VIII EPCC - Encontro Internacional de Produção Científica Cesumar. Maringá, Paraná: Editora CESUMAR. 2013.

10. Carniel IC, Figueiredo MAC. Um olhar da psicologia sobre as desordens temporomandibulares. In: Felício CM, Trawitzki LVV(org). Interfaces da Medicina, odontologia e fonoaudiologia no complexo cérvico-craniofacial. Pró-Fono. 2009. Vol.1. p.119-34.

11. Almondes KM, Araújo JF. Padrão do ciclo sono-vigília e sua relação com a ansiedade em estudantes universitários. Estudos de Psicologia. 2003;8(1):37-43.

12. Sousa DA, Moreno AL, Gauer G, Manfro GG, Koller $\mathrm{SH}$. Revisão sistemática de instrumentos para avaliação de ansiedade na população brasileira. Avaliação Psicológica. 2013;12(3):397-410.

13. Borini CB, Duarte CL, Amorim MM, Berzin F. Análise da Influência da ansiedade sobre o sinal eletromiográfico. Rev. Gaúcha Odontológica. 2010;58(2):225-30.

14. Kroll CD. Avaliação da ansiedade e da atividade eletromiografica dos músculos elevadores da mandíbula em mulheres com disfunção temporomandibular: um estudo psicofísico. 2009. [Tese] Campinas (SP): Universidade Estadual 
de Campinas, Faculdade de Odontologia de Piracicaba, Piracicaba, SP. Disponível em http:// libdigi.unicamp.br/document/?code $=000470058$. Acesso em 30 mar. 2017.

15. Borini CB. Analise eletromiografica de músculos mastigatórios: variabilidade e influência da ansiedade. 2008. [Tese] Campinas (SP): Universidade Estadual de Campinas, Faculdade de Odontologia de Piracicaba, SP. Disponível em: http://libdigi.unicamp.br/ document $/$ ?code $=000438270$ Acesso em 30 mar. 2017.

16. Tartaglia GM, Sforz C. Eletromiografia de superfície dos Músculos mastigatórios; instrumentos, métodos, aplicações na prática clínica. In: Felício CM, Trawitzki LVV.(org). Interfaces da Medicina, odontologia e fonoaudiologia no complexo cérvicocraniofacial. Pró-Fono. 2009. Vol.1. p.31-50.

17. Machado NAG, Strini PJSA, Branco CA, Borges RN, Mazzetto MO, Fernandes Neto AJ et al. Eletromiografia aplicada às desordens temporomandibulares. Rev Odontol Bras Central. 2010;19(51):280-4.

18. Celinski Al, Cunal RS, Bonotto D, Farias AC, Cunali PA. Eletromiografia de superfície em disfunção temporomandibular: revisão sistemática. Rev Dor. 2013;14(2):147-50.

19. Spielberger CD, Gorsuch RL, Luchene RE. Manual for the State-trait anxiety inventory: self-evaluation questionnaire. Consulting Psychologists Press, Palo Alto, CA.1970.

20. Veríssimo SMAC. Relações entre ansiedadeestado e Ansiedade-traço, sintomas depressivos sensibilidade ao stresse em puérperas [Dissertação]. Lisboa (Portugal): Universidade Lusófona e Humanidades e Tecnologias; 2010.

21. Biaggio AM, Natalício L. Manual para o Inventário de Ansiedade Traço- Estado (IDATE). Rio de Janeiro: Centro Editor de Psicologia Aplicada (CEPA); 1979.

22. Gama MMA, Moura GS, Araújo RF, Silva FT. Ansiedade-traço em estudantes universitários de Aracaju (SE). Rev Psiquiatr. 2008;30(1):19-24.

23. Almeida AAF, Behlau M, Leite JR. Correlation between anxiety and communicative performance. Rev Soc Bras Fonoaudiol. 2011;16(4):384-9.

24. Pereira Junior FJ, Favilla EE, Dworkin S, Huggins K. Critérios de diagnóstico para pesquisa das disfunções temporomandibulares (RDC/TMD).
Tradução oficial para a língua portuguesa. JBC J Bras Clin Odontol Integr. 2004;8(47):384-95.

25. Nascimento GKBO, Silva EF, Cunha DA, Silva HJ. Protocolo de avaliação eletromiográfica em mastigação. In: Silva HJ (org). Protocolos de eletromiografia de superfície em Fonoaudiologia. Barueri (SP): Pró-Fono; 2013. p.15-26

26. Silva HJ, Oncins MC, Nascimento GKBO, Pernambuco LA, Albuquerque LCA, Cunha DA. Uso de protocolo de normalização do sinal eletromiográfico na mastigação e as relações com a eletromiografia. In: Rahal A, Oncins MC (orgs). Eletromigrafia de superfície na terapia miofuncional. 1‥ Ed. São José dos Campos: Pulso Editorial; 2014. p.79-90.

27. Soderberg GL, Knutson LM. A guide for use and interpretation of kinesiologic electromyographic data. Phys Ther. 2000;80(5):485-98.

28. Barberia E, Fernández-Frías L, Suárez-Clúa C, Saavedra D. Analysis of anxiety variables in dental students. Int Dent. Journal. 2004;54(6):445-9.

29. Peker L , Alkurt MT, Usta MG, Turkbay T . The evaluation of perceived sources of stress and stress levels among Turkish dental students. Int Dent J. Apr. 2009;59(2):103-11.

30. Acharya S. Factors affecting stress among Indian dental students. J Dent Educ. 2003;67(10):1140-8.

31. Morse Z, Dravo U. Stress levels of dental students at the Fiji School of Medicine. Eur J Dent Educ. 2007;11(2):99-103.

32. Sanders AE, Lushington K. Efeito do estresse percebido no desempenho dos alunos na escola dental. J Dent Educ. 2002;66(1):75-81.

33. Sousa EF, Moreira TR, Santos LHG. Correlação do nível de ansiedade e da qualidade de vida com os sinais e sintomas da disfunção temporomandibular em universitários. ClipeOdonto. 2016;8(1):16-21.

34. Kino K, Sugisaki M, Haketa T, Amemori Y, Ishikawa $\mathrm{T}$, Shibuya $\mathrm{T}$ et al. The comparison between pains, difficulties in function, and associating factors of patients in subtypes of temporomandibular disorders. J Oral Rehabil. 2005;32(5):315-25.

35. Manfredini D, Bandettini di Poggio A, Cantini E, DellÓsso L, Bosco M. Mood and anxiety psychopathology and temporomandibular disorder: a spectrum approach. J Oral Rehabil. 2004;31(10):933-40.

36. Liu ZJ, Yamagata K, Kasahara Y, Ito G. Electromyographic examination of jaw muscles in relation to symptoms and occlusion of patients with 
temporomandibular joint disorders. J Oral Rehabil. 1999;26(1):33-47.

37. Pinho JC, Caldas FM, Mora MJ, Santana-Penín $U$. Electromyographic activity in patients with temporomandibular disorders. J Oral Rehabil. 2000;27(11):985-90.

38. Chimendes LH. Desenvolvimento de um gnatodinamômetro digital para estudo e análise da força dos músculos da mastigação. [tese]. Guaratinguetá (SP): Universidade Estadual Paulista; 2013.

39. Mongini F, Tempia-Valenta G, Conserva E. Habitual mastication in dysfunction: a computer-based analysis. J Prosthet Dent. 1989;61:484-94.

40. Nielsen IL, McNeill C, Danzig W, Goldman S, Levy $\mathrm{J}$, Miller AJ. Adaptation of craniofacial muscles in subjects with craniomandibular disorders. Am J Orthod Dentofac Orthoped. 1990;97:20-34. 